\title{
Acute myeloid leukemia and myelodysplastic syndromes related to radiation
}

INSERM

\section{Source}

INSERM. (1999). Orphanet: an online rare disease and orphan drug data base. Acute myeloid leukemia and myelodysplastic syndromes related to radiation. ORPHA:164726

Acute myeloid leukemia and myelodysplastic syndromes related to radiation represent a subgroup of therapy-related myeloid neoplasms (t-MN), associated with treatment of an unrelated neoplastic disease with radiation. The neoplastic cells typically harbor unbalanced aberrations of chromosomes 5 and 7 (monosomy 5/del(5q) and monosomy 7/del(7q)) or a complex karyotype. Patients frequently present with multilineage dysplasia and cytopenias 5-10 years after exposure. 